\title{
Supporting Information for: Robust Unipolar Electron Conduction using an Ambipolar Polymer Semiconductor with Solution-Processable Blends
}

\author{
Michael J. Ford*,,$\|,\urcorner, \dagger$, Mitsuharu Suzuki ${ }^{\perp, \Delta}$, Colin R. Bridges $\urcorner$,, , Karen C. Bustillo ${ }^{\#}$, Martin \\ Seifrid ${ }^{\|,} ¥$, Ming Wang $\left.{ }^{\|,}\right\urcorner$, $¥$, Hiroko Yamada ${ }^{\perp}$, Thuc-Quyen Nguyen $\left.{ }^{\|,}\right\urcorner$, $¥$, Guillermo C. Bazan ${ }^{*}, \S$, \\ $\|, \neg, ¥$ \\ §Materials Department, "Center for Polymers and Organic Solids, ᄀMitsubishi Chemical Center for Advanced \\ Materials, and ${ }^{¥}$ Department of Chemistry and Biochemistry, ${ }^{\dagger}$ Department of Chemical Engineering, University \\ of California, Santa Barbara, California, United States \\ ${ }^{\perp}$ Division of Materials Science, Nara Institute of Science and Technology, 8916-5 Takayama-cho, Ikoma, Nara \\ 630-0192, Japan \\ ${ }^{\Delta}$ Department of Material and Life Science, Graduate School of Engineering, Osaka University, 2-1 Yamadaoka, \\ Suita, Osaka 565-0871, Japan \\ \#National Center for Electron Microscopy, Molecular Foundry, Lawrence Berkeley National Laboratory, \\ Berkeley, California, United States
}




\section{Detailed Experimental Procedures:}

Thin-Film Processing. Stock solutions of DPP (1-Material) and TBP derivatives were dissolved in chlorobenzene and mixed to obtain the corresponding blend weight ratio. Two different batches of DPP were obtained from 1-Material with one labeled as "low molecular weight". The manufacturer indicated that the low molecular weight batch was extracted from chloroform with a number average molecular weight of $25 \mathrm{kDa}$, and the higher molecular weight batch was extracted from chlorobenzene with a number average molecular weight of $40 \mathrm{kDa}$. Both batches had dispersity of about 2.5. Soluble precursors for CuBP and TBP were provided by Mitsubishi Chemicals. The synthesis for C12-ZnBP and TBP precursors are described below. The blend concentration was 5 $\mathrm{mg} / \mathrm{mL}$ with respect to the total DPP + TBP derivative content. Thin films were processed by spincoating at $2500 \mathrm{rpm}$. Films were annealed at $200{ }^{\circ} \mathrm{C}$ on a hot plate unless specified otherwise. For experiments where annealing time was successively increased, the sample was placed on the hot plate for the time indicated and immediately quenched to room temperature on an aluminum surface. $300 \mathrm{~nm} \mathrm{SiO}{ }_{2}$ dielectric/doped $\mathrm{Si}$ (University Wafer) substrates were sonicated in acetone and isopropanol for $3 \mathrm{~min}$ in each solvent and then dried in an oven under ambient atmosphere at $120{ }^{\circ} \mathrm{C}$ for $10 \mathrm{~min}$. BCB (Cyclotene 3022-46) was purchased from Dow Chemicals and diluted by volume to a ratio of 1:46 with toluene. The dielectric layer was spun at $4000 \mathrm{rpm}$ and dried on a $100{ }^{\circ} \mathrm{C}$ hot plate for about $5 \mathrm{~min}$. The dielectric was cured in an $\mathrm{N}_{2}$ glovebox environment for at least $2 \mathrm{~h}$ at a hot plate temperature of $240-250{ }^{\circ} \mathrm{C}$. The final dielectric thickness measured by profilometry was about 30$40 \mathrm{~nm}$ for a total dielectric thickness $\left(\mathrm{SiO}_{2}+\mathrm{BCB}\right)$ of about 330-340 nm. The semiconductor layer thickness measured by profilometry and cross section STEM was about $20-40 \mathrm{~nm}$. Ag contacts (80 $\mathrm{nm}$ ) were deposited by thermal evaporation. Bottom-gate, top-contact field-effect transistors were fabricated for all blend compositions.

\section{TBP synthesis:}

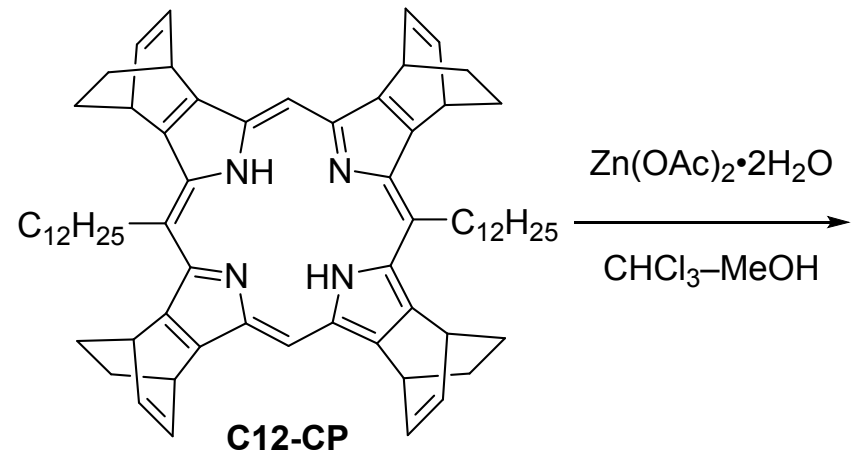

(mixture of stereoisomers)

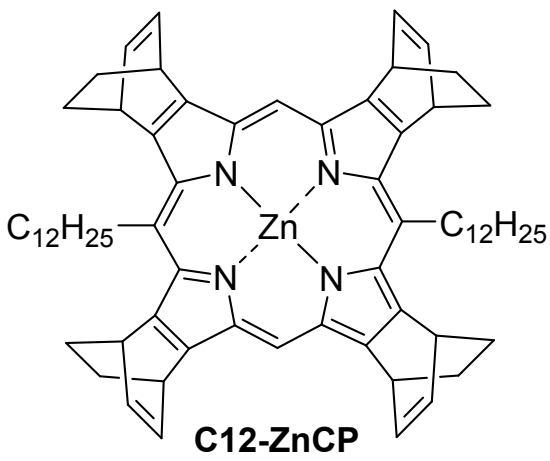

(mixture of stereoisomers)

C12-CP, which was synthesized as previously reported ${ }^{1},(81.3 \mathrm{mg}, 84.7 \mu \mathrm{mol})$ was dissolved in $25 \mathrm{~mL}$ of $\mathrm{CHCl}_{3}$, to which a solution of $\mathrm{Zn}(\mathrm{OAc})_{2} \cdot 2 \mathrm{H}_{2} \mathrm{O}(102 \mathrm{mg}, 0.465 \mathrm{mmol})$ in $2 \mathrm{~mL}$ of $\mathrm{MeOH}$ was added. The mixture was stirred for $3 \mathrm{~h}$ at room temperature before washing with saturated $\mathrm{NaHCO}_{3}(\mathrm{aq})$. The aqueous phase was extracted with $\mathrm{CHCl}_{3}$. The combined organic phase was washed with deionized water and brine, dried over $\mathrm{Na}_{2} \mathrm{SO}_{4}$, and filtered. The filtrate was passed through a short pad of $\mathrm{SiO}_{2}$, and then evaporated. The crude product was recrystallized from $\mathrm{CHCl}_{3} / \mathrm{MeOH}$ to afford $\mathrm{C} 12-\mathrm{ZnCP}$ as a purple solid (76.4 mg, $74.7 \mu \mathrm{mol}, 88 \%) .{ }^{1} \mathrm{H}$ NMR $\left(\mathrm{CDCl}_{3}\right): \delta 0.89(\mathrm{~s}, 6 \mathrm{H}), 1.30-2.20$ 
(multiple peaks, 44H), 2.76, 2.90, 2.97 ( 3 peaks, $4 \mathrm{H}$ in total), 5.18, 5.28, 5.37 (3 peaks, 4H in total), $5.76(\mathrm{~s}, 8 \mathrm{H}), 7.13-7.20(\mathrm{~m}, 8 \mathrm{H}), 10.19(\mathrm{~s}, 2 \mathrm{H}) ;{ }^{13} \mathrm{C}\left\{{ }^{1} \mathrm{H}\right\} \mathrm{NMR}\left(\mathrm{CDCl}_{3}\right): \delta 14.2,22.7,27.1,27.5,27.6,28.2$, 29.4, 29.7, 29.8, 30.2, 30.6, 30.6, 31.9, 34.7, 34.9, 35.0, 36.1, 38.9, 39.2, 39.3, 40.9, 41.0, 96.6, 119.9, $120.2,120.3,137.0,140.5,143.9,143.9,147.9,148.0,148.0,151.3$; IR (ATR): $\tilde{v}\left[\mathrm{~cm}^{-1}\right] 684$ (s), 755 (m), $818(\mathrm{w}), 842(\mathrm{~s}), 892(\mathrm{w}), 1017(\mathrm{w}), 1064(\mathrm{~m}), 1082(\mathrm{w}), 1102(\mathrm{~m}), 1125(\mathrm{w}), 1141(\mathrm{w}), 1154$ (s), 1212 (w), 1230 (w), 1337 (w), 1441 (w) 1458 (w), 1468 (w), 1610 (w), 2851 (m), 2921 (s), 2954 (m), $3048(\mathrm{w})$; HRMS (MALDI-TOF, DCTB + TFANa): $m / z$ calculated for $\mathrm{C}_{68} \mathrm{H}_{84} \mathrm{~N}_{4} \mathrm{Zn}^{\bullet+}\left(\mathrm{M}^{\bullet+}\right.$ ) 1020.5982 , found 1020.5985 . Note that most of the ${ }^{1} \mathrm{H}$ NMR signals were observed as broad peaks, and coupling constants could not be determined.

Device Characterization. The mobility for blend devices was obtained by fitting the gradual channel approximation to the saturation regime transfer characteristics, with a channel width of $2.5 \mathrm{~mm}$ and channel length of $160 \mu \mathrm{m}$. Devices were measured under nitrogen in a glovebox using a Signatone 1160 probe station and Keithley 4200 semiconductor parametric analyzer. Mobility values calculated from a gate voltage range of about $20 \mathrm{~V}$ to $50 \mathrm{~V}$ at a source-drain voltage of $80 \mathrm{~V}$.

Morphological Characterization. Grazing incidence wide angle X-ray scattering (GIWAXS) measurements were performed at beamline 11-3 at the Stanford Synchrotron Radiation Lightsource with an X-ray energy of $12.7 \mathrm{keV}$ at a $250 \mathrm{~mm}$ sample-detector distance. The measurements were calibrated using an $\mathrm{LaB}_{6}$ standard. Samples were scanned in a He environment at an incident angle of $0.15^{\circ}$. AFM images were obtained in air using an Innova atomic force microscope (AFM). Transmission electron microscopy (TEM) samples were prepared by first spin-coating a $10 \mathrm{mg} / \mathrm{mL}$ solution of sodium polystyrenesulfonate in water on top of a clean silicon dioxide substrate. A thin (ca. $30 \mathrm{~nm}$ ) layer of cyclotene (Dow Chemical Company, also referred to as BCB) was used as a film support layer. The semiconductor blend was spun on top and floated off in onto an ultrathin carbon film on lacey carbon Au TEM grid (Ted Pella). High-angle annular dark-field (HAADF) scanning transmission electron microscopy (STEM) images were obtained using an FEI TitanX 60-300 TEM operating at $60 \mathrm{kV}$ with a HAADF detector. A Bruker windowless energy dispersive X-ray spectroscopy (EDS) detector was used for EDS. For cross-section HAADF-STEM coupled with EDS, the sample was first prepared using an FEI Helios Dualbeam Nanolab 650. A substrate and 50:50 wt. content CuBP:DPP thin film annealed at $200{ }^{\circ} \mathrm{C}$ was prepared identical to one prepared for OFET testing. An aluminum layer was deposited to prevent charging during etching. A portion of the sample (e.g., $10 \mu \mathrm{m} \times 3 \mu \mathrm{m}$ ) was masked with Pt followed by ion beam etching and extraction. The crosssection was attached to a TEM grid. The faces of the cross-section were further etched until sufficiently thin for HAADF-STEM imaging. Resonant soft X-ray scattering (RSoXS) was performed at beamline 11.0.1 at the Advanced Light Source with an X-ray energy of $284.2 \mathrm{eV}$. Samples were prepared atop a silicon nitride membrane $(100 \mathrm{~nm})$ supported by a silicon frame (Norcada). XPS studies were performed on a Kratos Axis Ultra system using a monochromated Al X-ray source. Films were cast onto silicon substrates in a glovebox under nitrogen atmosphere and transported for analysis in an air-free chamber. 


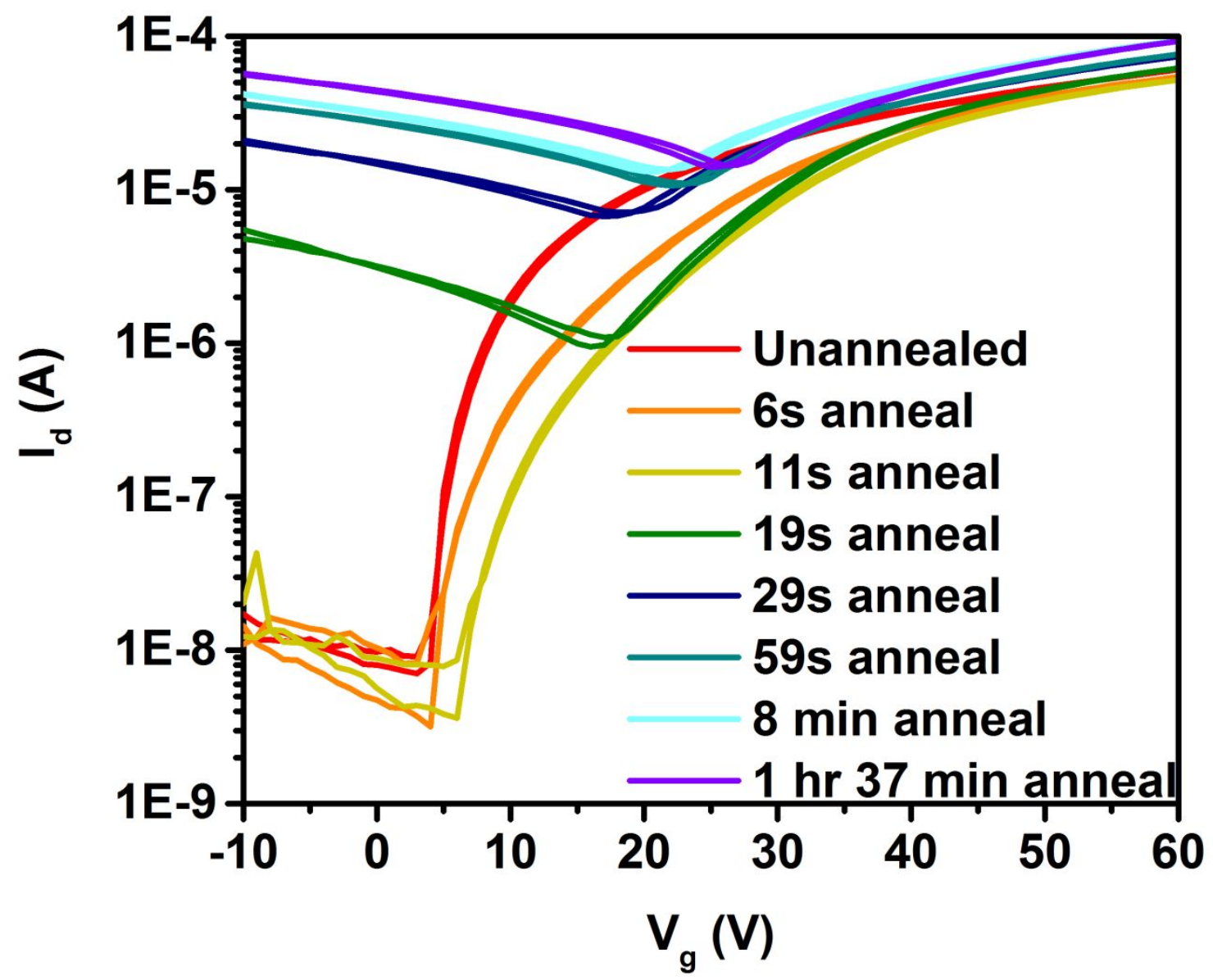

Figure S1. OFET characteristics of a representative TBP:DPP blend film with different annealing conditions. After the blend was annealed for $>10$ s, the hole conduction began increasing. 
A)

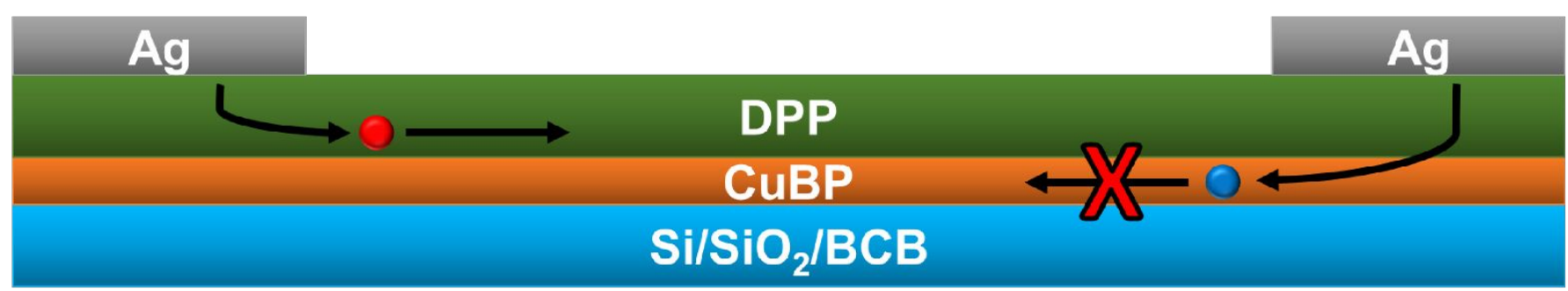

B)

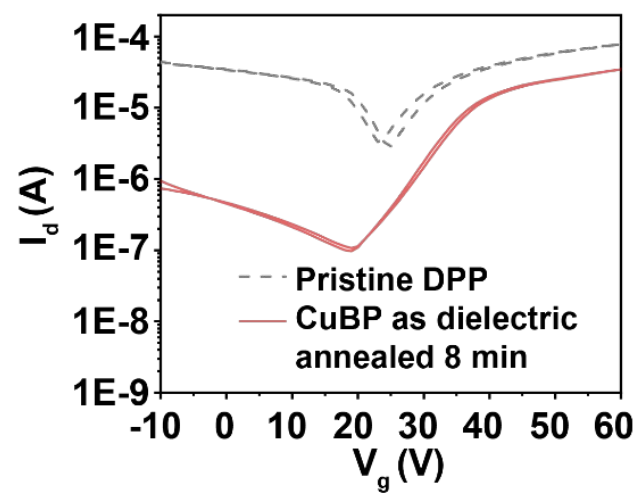

C)

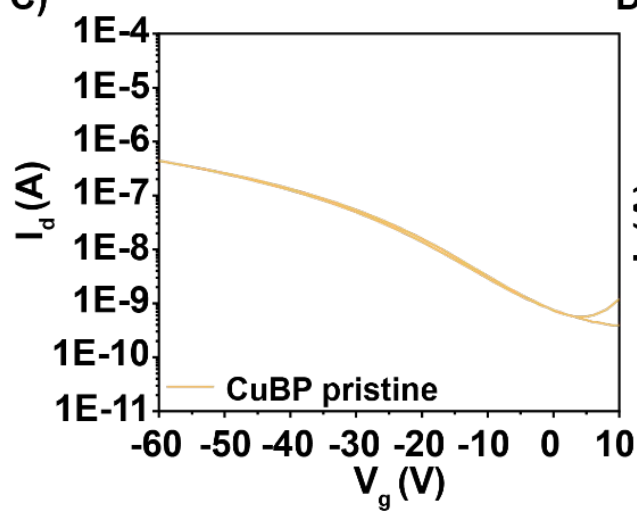

D)

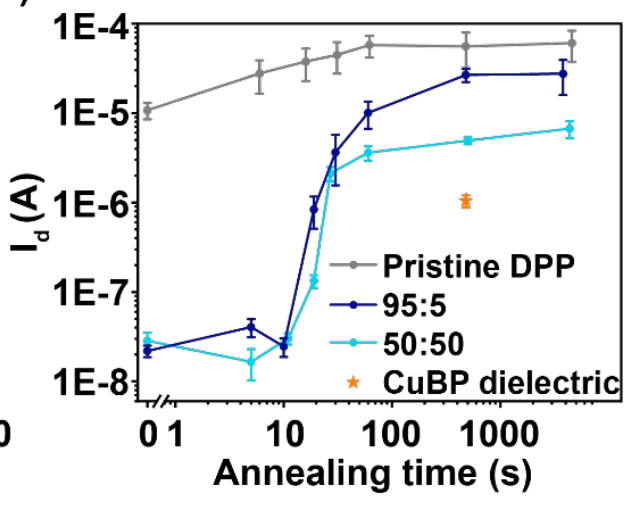

Figure S2. (A) Cross section schematic of sequential deposition to form a quasi-heterostructure of CuBP and DPP. The soluble precursor was spun atop the dielectric layer and subsequently converted to the insoluble CuBP. Then the semiconducting polymer DPP was spun atop the CuBP layer. The red ' $X$ ' indicates that the CuBP layer hindered hole transport. (B) The OFET could be annealed for $>8 \mathrm{~min}$ while maintaining improved on/off ratios with CuBP confined to the accumulation layer. The OFET was measured with the drain-source voltage equal to $80 \mathrm{~V}$. (C) $p$-channel transfer characteristics of a pristine CuBP OFET (annealed for $8 \mathrm{~min}$ at $200^{\circ} \mathrm{C}$ ). The OFET was measured with the drain-source voltage equal to $-80 \mathrm{~V}$. (D) Figure $2 \mathrm{C}$ can be compared with the value for the CuBP quasiheterostructure. At least 3 devices were tested and the current at $-10 \mathrm{~V}$ is represented by the y-axis. 

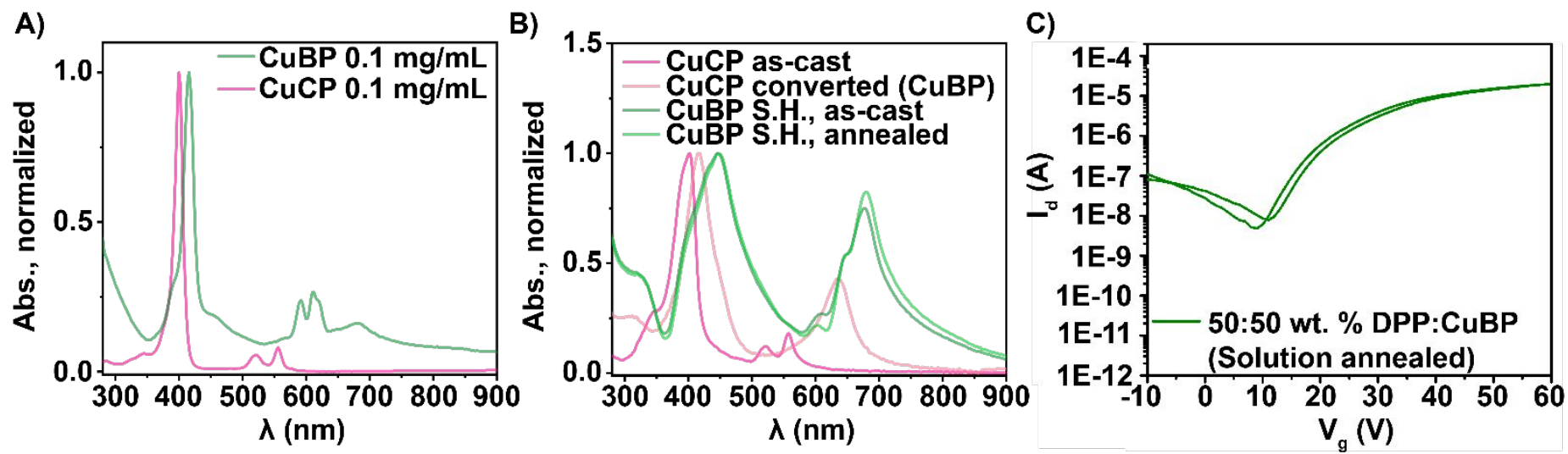

Figure S3. (A) Solution UV-vis of a CuCP solution and a CuBP solution. The CuBP solution was formed by gently heating the CuCP solution for an extended period, resulting in a green solution. (B) Thin film UV-vis of CuCP and CuBP films that were formed from CuCP (pink traces) or from the heated $\mathrm{CuBP}$ solution. S.H. is used to abbreviate "solution heated", which represents films formed from CuBP solutions (UV-Vis shown in (A)). A noticeable shift in the absorption spectrum occurred for the CuCP films relative to the $\mathrm{CuBP}$ films, indicating that the $\mathrm{CuBP}$ solutions were primarily comprised of a converted form of CuCP. (C) Transfer characteristics of an unannealed OFET case from the solutionheated CuBP solution blended with DPP. 


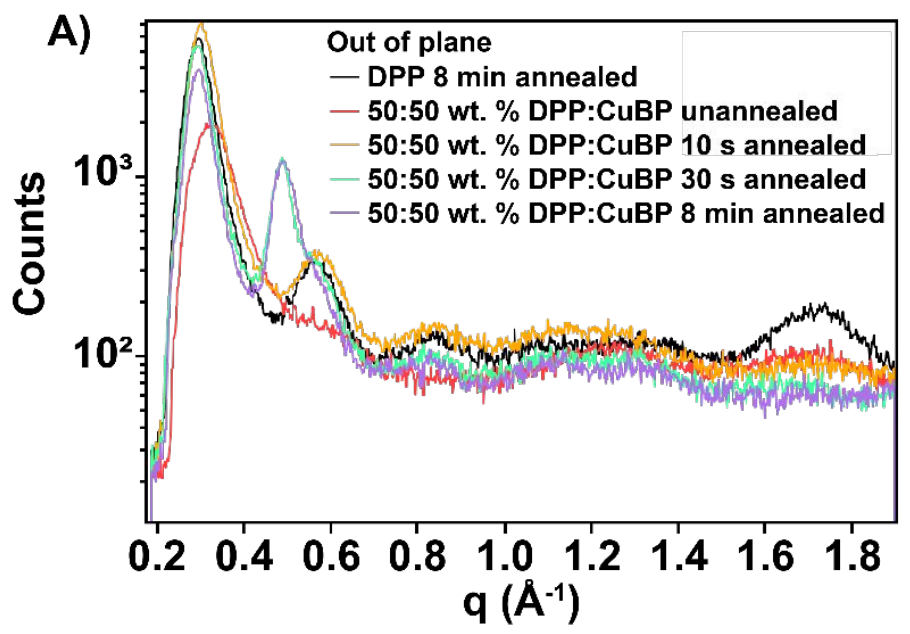

C)

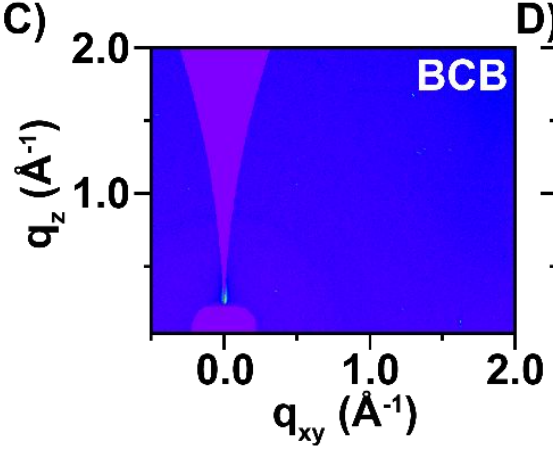

D)

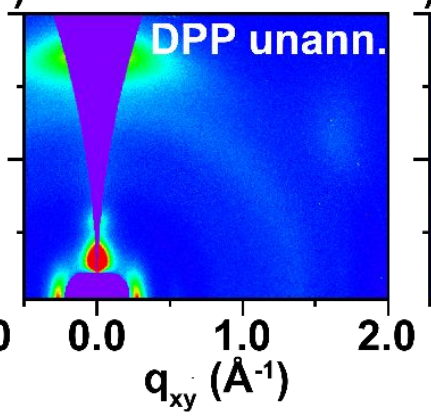

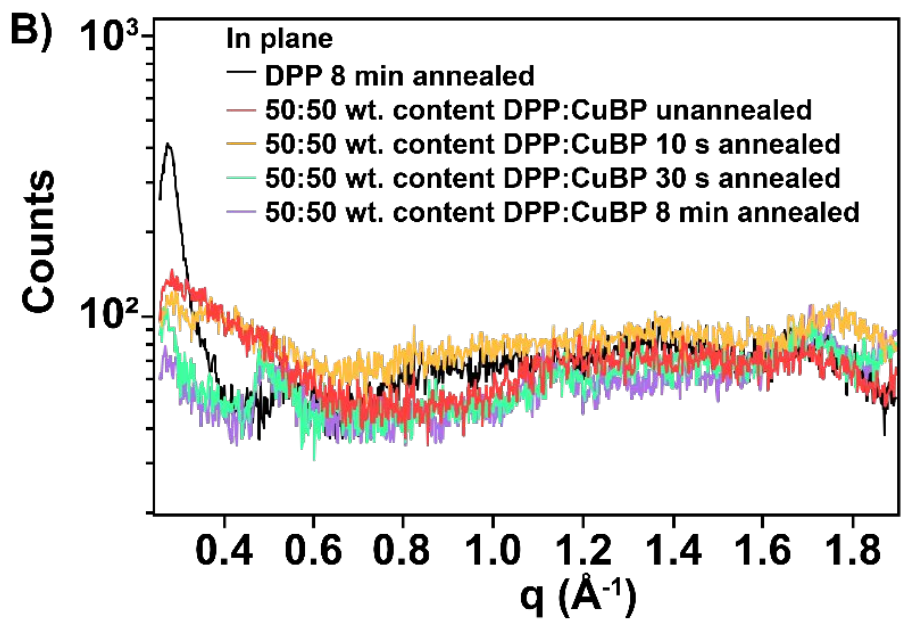

E)

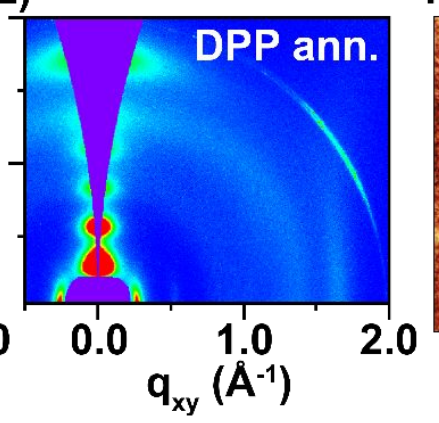

F)

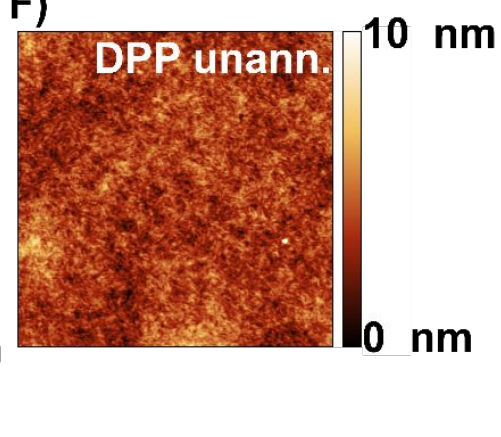

Figure S4. (A) Nominally out-of-plane and (B) in-plane sector plots of DPP and related blends. Sector plots were taken from the vertical at $\mathrm{q}_{\mathrm{xy}}=0$ at $9-20^{\circ}$ and at $73-84^{\circ}$. For reference, the GIWAXS images of BCB (C), unannealed DPP (D), and annealed DPP (200 $\left.{ }^{\circ} \mathrm{C},>8 \mathrm{~min}\right)$ (E) are provided as well as the AFM of the unannealed DPP thin film, which is $5 \times 5 \mu \mathrm{m}(\mathrm{F})$. 


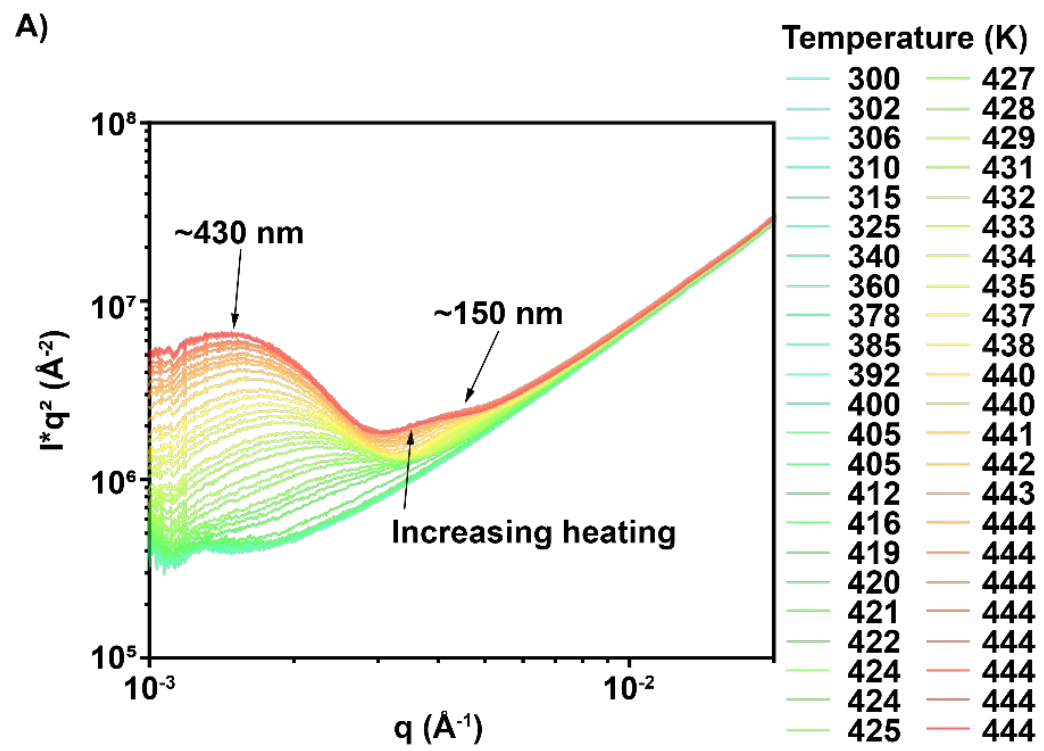

B)

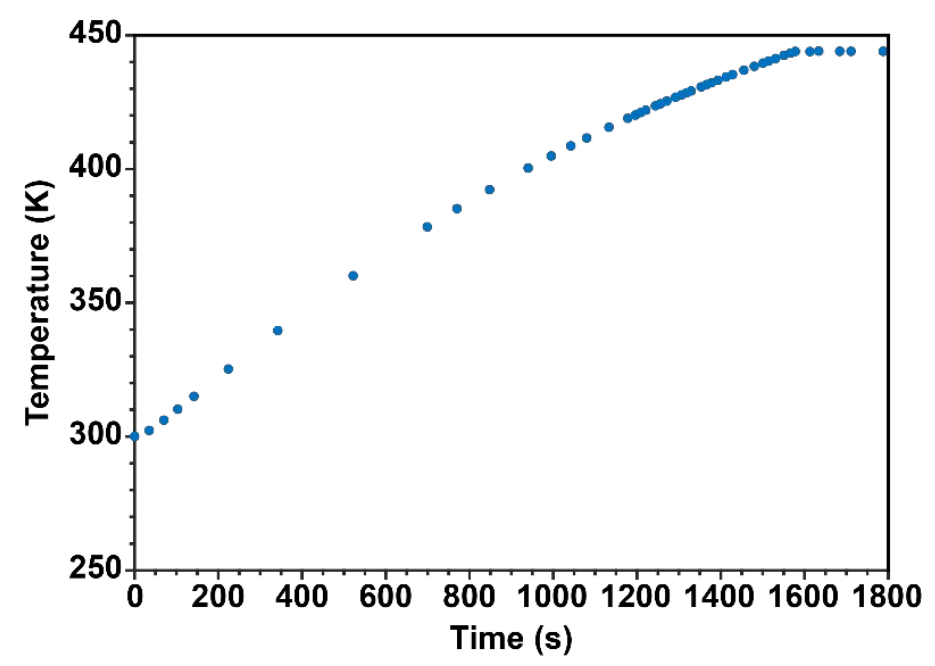

Figure S5. (A) RSoXS of a 50:50 wt. content DPP:CuBP thin film annealed in-situ. The beam energy was set to $284.2 \mathrm{eV}$. Since the RSoXS sample chamber is under high vacuum, the morphological change could only be monitored while ramping the temperature to ca. $444 \mathrm{~K}$. An increase in two peaks is observed as the CuBP crystallizes. (B) The temperature of the sample heater was tracked during ramping.
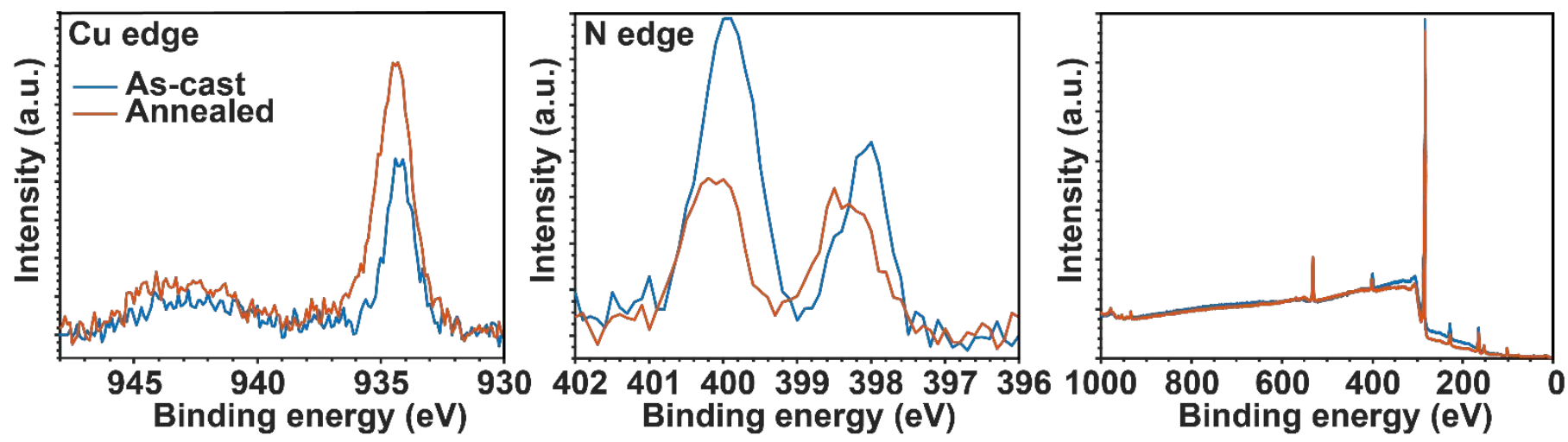

Figure S6. XPS of DPP:CuBP 50 wt. \% blend annealed and as cast. The background-subtracted copper and nitrogen edges are shown along with the binding energy survey. 


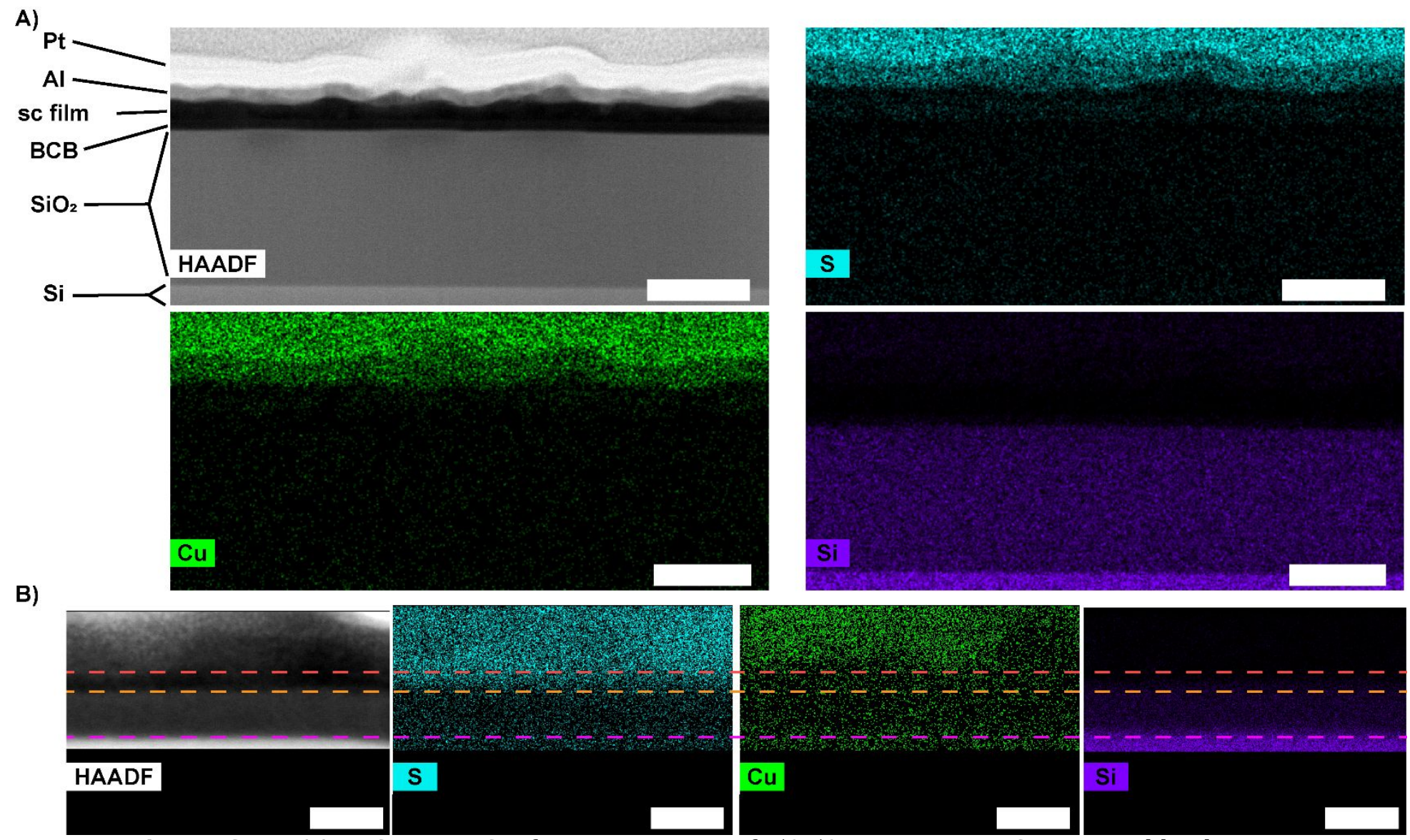

Figure S7. HAADF-STEM-EDS of cross-sections of 50:50 wt. content CuBP:DPP blends atop $\mathrm{Si} / \mathrm{SiO}_{2} / \mathrm{BCB}$ substrates. The films were coated with $\mathrm{Al}$ before being extracted and etched using a Focused Ion Beam. The architecture is shown in (a). The scale bar in (a) is $200 \mathrm{~nm}$. To image phase separation, a zoomed cross-section is shown (b) where the pink dashed line guides the eye to the $\mathrm{SiO}_{2} / \mathrm{BCB}$ interface; the orange dashed line guides the eye to the $\mathrm{BCB} /$ semiconductor film interface; and the red trace guides the eye to approximately where the phase-separated interface lies. The scale bar in (b) is $30 \mathrm{~nm}$. 


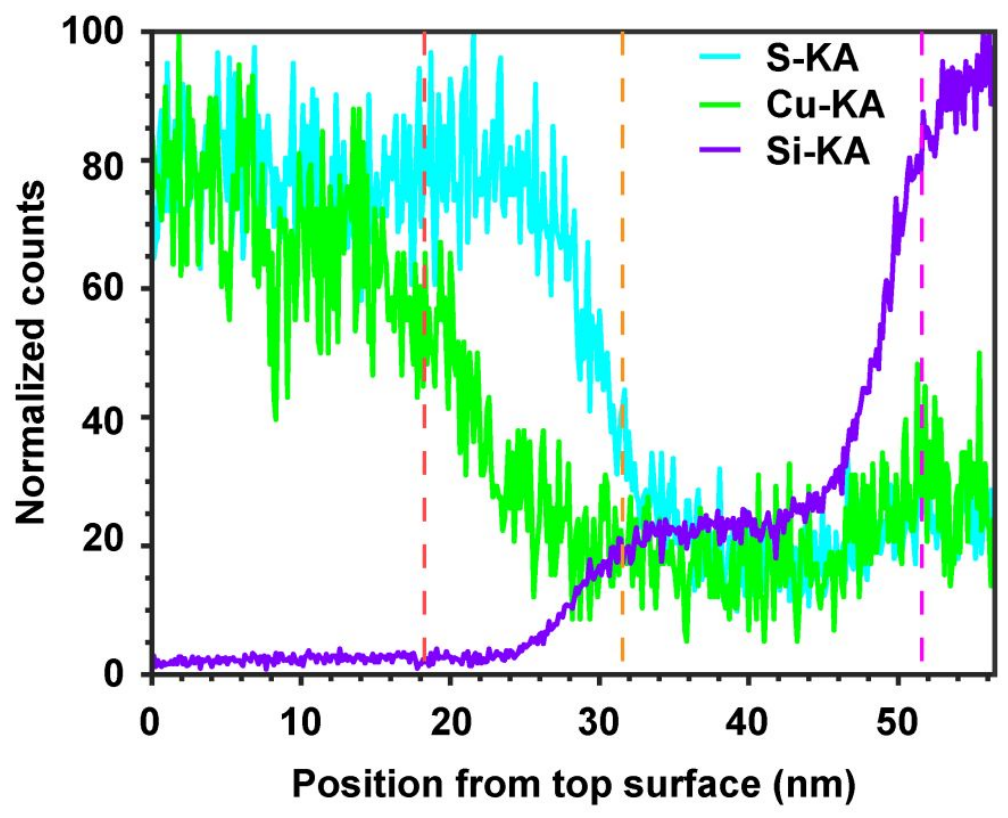

Figure S8. EDS line trace (corresponding to gold arrow on the bottom of the figure) of Figure S7B. The dashed traces guide the eye to the phase-separated interface (red), the BCB/semiconductor interface(orange), and the $\mathrm{SiO}_{2} \mathrm{BCB}$ interface (pink) and correspond to the dashed traces in Figure S7B.
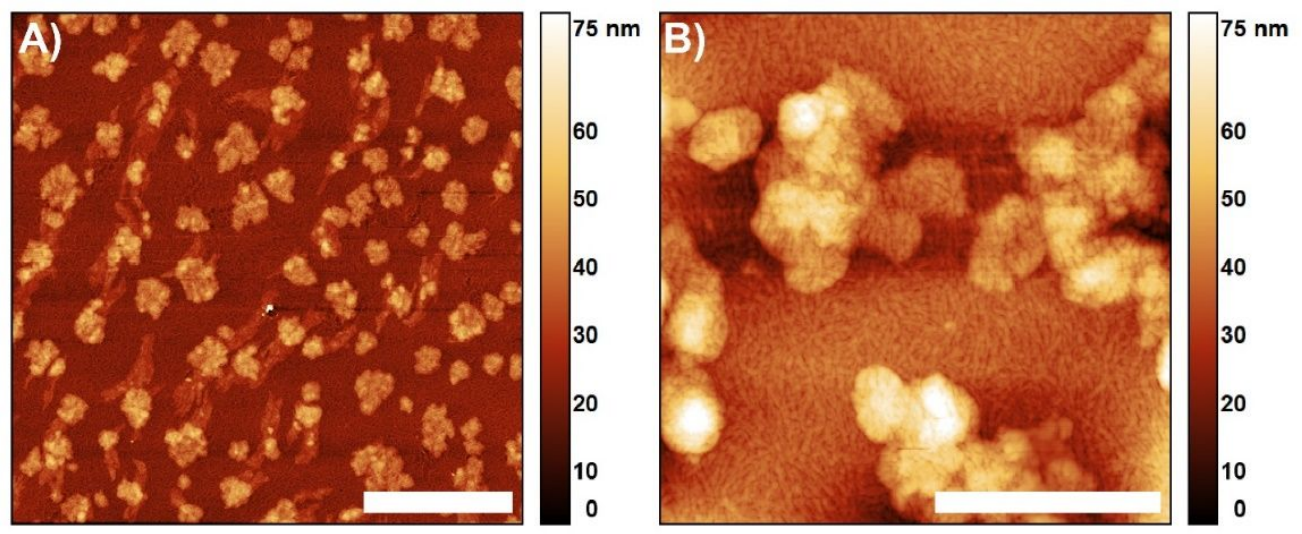

Figure S9. AFM images of 50:50 wt. content C12-ZnBP:DPP blends. The scale bars are $5 \mu \mathrm{m}(\mathrm{A})$ and $2 \mu \mathrm{m}(\mathbf{B})$. 


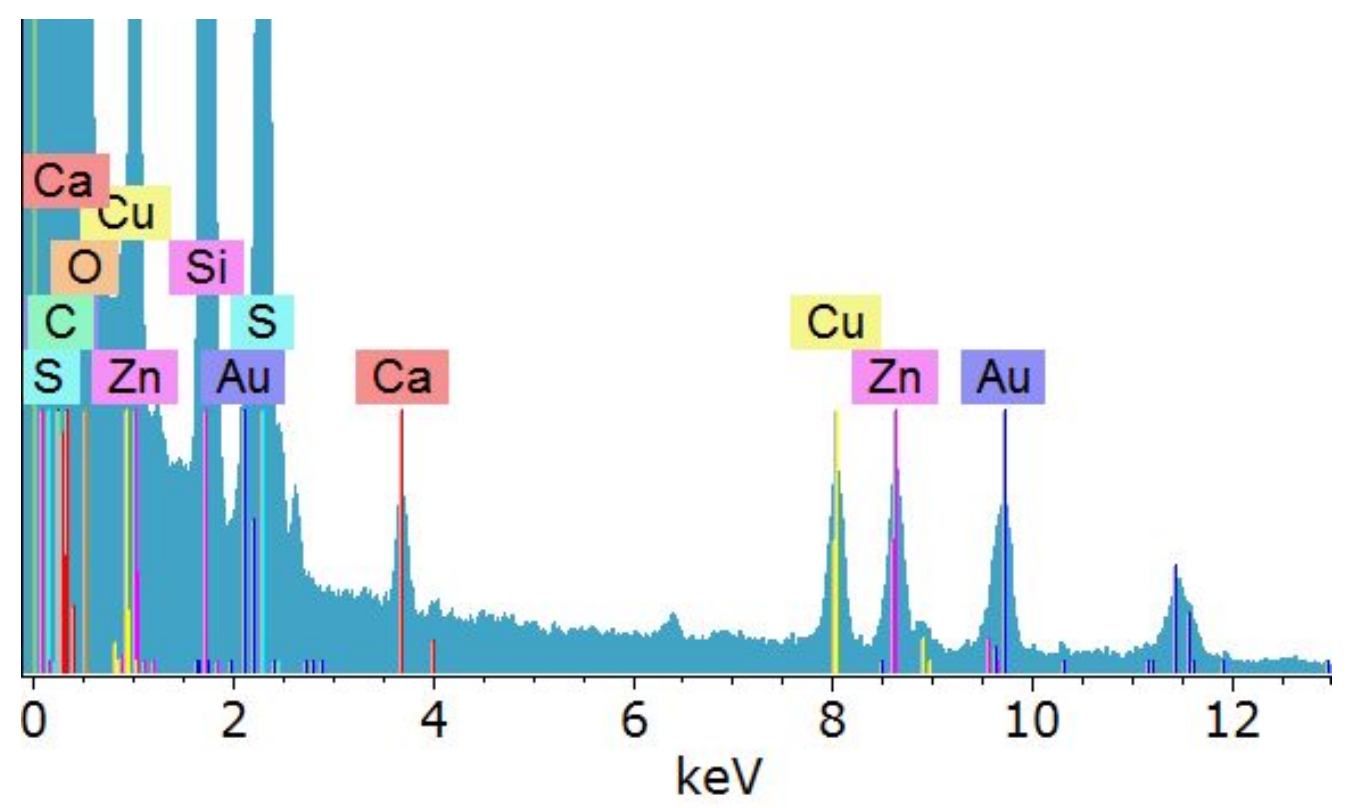

Figure S10. Energy spectrum of map shown in Figure 5C. Y-axis is in arbitrary units.

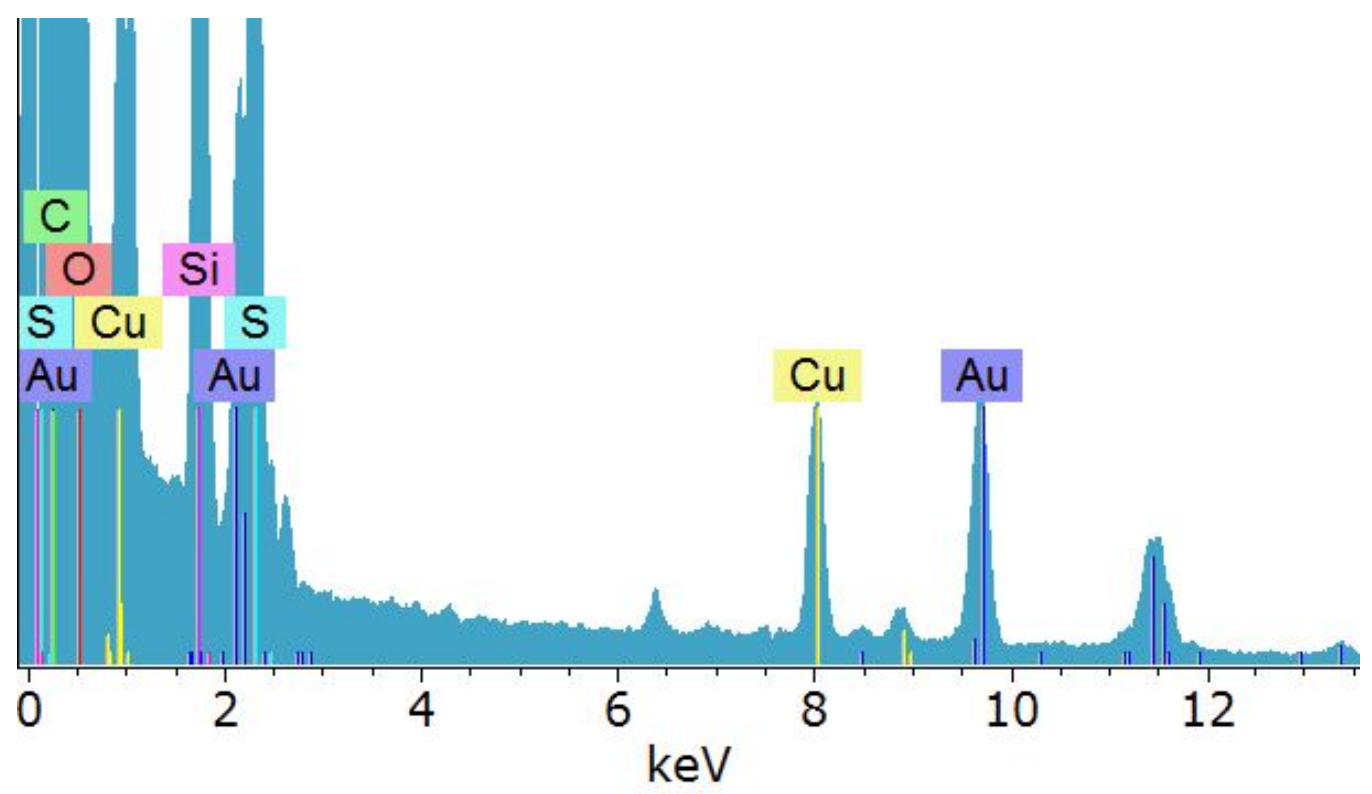

Figure S11. Energy spectrum of map shown in Figure 5F. Y-axis is in arbitrary units.

1. Kojima, H.; Abe, R.; Fujiwara, F.; Nakagawa, M.; Takahashi, K.; Kuzuhara, D.; Yamada, H.; Yakiyama, Y.; Sakurai, H.; Yamamoto, T.; et al. Universality of the Giant Seebeck Effect in Organic Small Molecules. Mater. Chem. Front. 2018, 2 (7), 1276-1283. https://doi.org/10.1039/C7QM00596B. 